\title{
Removal Modeling of Encapsulated L.minor by Alginate Microspheres
}

\author{
Esra Üçüncü TUNCA ${ }^{1 *}$, Hasan TÜRE ${ }^{2}$
}

\begin{abstract}
The aim of the study was to model the efficiency of different sorbents (Lemna minor $(L)$, alginate microspheres (A) and encapsulated L.minor (caps $\mathrm{A}+\mathrm{L})$ ) on the removal of malachite green dye(MG) by using regression analysis. One other purpose was to specify the effects of encapsulation on the removal process. Linear and cubic estimation models were constructed and it was seen that $\mathrm{R}^{2}$ values of cubic models were higher (0.988-1.0). It was observed that group (A) was less successful on MG removal compared to other groups $(L>\operatorname{caps} A+L>A)$. Encapsulation increased the removal capacity of microspheres but still did not attain the efficiency of $(L)$ group that was $(70.22-85.69 \%)$.
\end{abstract}

Keywords: Alginate microsphere, encapsulation, malachite green, removal, regression 


\section{INTRODUCTION}

Concentration amounts of contaminants such as dye, nanoparticles and heavy metals, rapidly increase in environment due to enhance in industry and hence become a threat for environment. Plenty of toxic dye are discharged into aqueous medium and cause, directly or indirectly, serious health problems on organisms (Naushad et al., 2015). In order to remove these contaminants, which are known to have serious toxic effects on organisms (Biradar et al., 2016; Clar et al., 2016; Üçüncü et al., 2014), from aqueous mediums, various methods such as chemical precipitation, ion change, nano-filtration, electrolytic reduction and membrane filtration are used (Idris et al., 2012; Zheng et al., 2016; Zhou et al., 2015). However, sometimes these methods can be very expensive (Ngah and Fatinathan, 2010) and yet insufficient (Zhou et al., 2009) for the removal of some toxic heavy metal ions. Therefore, more environment friendly, economical and efficient methods such as bioremediation, adsorption and sorption are preferred nowadays (Li et al., 2011; Naushad et al., 2015).

Adsorption method is highly suitable in removal studies since it is environmentally friendly, economical and has high adsorption efficiency in removal processes (Vu et al., 2017; Wang et al., 2016; Wu et al., 2016). For this purpose several types of adsorbents have been developed such as activated carbon, zeolites, chitosan, alginate, meso-silica (Liang et al., 2016). One of best materials used in encapsulation process is the alginate, which is a linear biopolymer (Ociński et al., 2016). The most important reasons preferring alginate in encapsulation are that nontoxicity, high biocompatibility and the crosslink ability with cations (Vu et al., 2017). Since the unsolved alginate grains own carboxyl groups, which can react with metal cations on beads, can be used as biosorbent of various heavy metals (Hong et al., 2016). Due to its high adsorption capacity for some metals, like $\mathrm{Cu}$ (II), $\mathrm{Cd}$ (II), $\mathrm{Pb}$ (II), $\mathrm{Ni}(\mathrm{II})$ and $\mathrm{Hg}$ (II), alginate has potential in removal of toxic contaminants (Dubey et al., 2016). Alginate is also can be used in adsorption of dye intensively present in wastewater (Zhu et al., 2014).

There are different types of dye one of which the basic dye, known as also cationic dye, can exhibit toxic effects even in trace amounts (Issa et al., 2014). Malachite green (MG), a cationic dye, mostly used in coloring of silk, acrylic and wool (Khan et al., 2014); can be discharged into water with textile waste. MG can also be used as antiseptic and fungicidal agent and it is considered to have carcinogenic and mutagenic effects on human being (Soni et al., 2014). Furthermore, MG is used as food additive and in food coloring and known to be highly toxic for mammalian cells (Zhou et al., 2015). For these reasons, the removal of these toxic contaminants from medium is a very important issue.

In this paper, L.minor, alginate microspheres and L.minor encapsulated in alginate microspheres were used as adsorbents for the removal of the malachite green cationic dye. The main purpose of this study is to evaluate and compare the efficiency of these adsorbents in removal of MG and construct a statistical model by regression analysis. One other aim of this study is to determine the effects (positive or negative) of encapsulation on removal efficiency (particularly for certain adsorbent and toxic contaminant).

\section{MATERIALS AND METHODS}

\section{Preparation of Sorbents}

In this study L.minor, an aquatic macrophyte, and microspheres, synthesized from alginate, were used. The test organism L.minor was provided from the culture in Faculty of Marine Sciences, Ordu University and accommodated to test medium. After washing with distilled water, L.minor were dried at $60{ }^{\circ} \mathrm{C}$ for 24 hours and then the dried samples were granulated (Jerold and Sivasubramanian, 2016). Sodium alginate microspheres are prepared by using ionic gelation method. In applying of this method first of all, homogenous sodium alginate solution, at a concentration of $(1 \% \mathrm{wt} / \mathrm{v})$, is prepared with 
magnetic stirring. This solution is then dropped into the prepared calcium chloride solution (5\%,w/v) by using pipette tip $(1 \mathrm{~m} \mathrm{~L})$. Alginate microspheres incubated for 24 hours at $\mathrm{CaCl}_{2}$ bath and then rinsed with deionized water for three times before the experiments (Pandey et al., 2015). Obtained microspheres were dried at room temperature until constant weight.

\section{Chemicals}

Sodium alginate, used in the experiments, was provided from Sigma-Aldrich and calcium chloride $\left(\mathrm{CaCl}_{2}\right)$ was obtained from Tekkim, Turkey. For the removal experiments malachite green (molecular formula: $\mathrm{C}_{52} \mathrm{H}_{54} \mathrm{~N}_{4} \mathrm{O}_{12}$; and molecular weight: $927.01 \mathrm{~g} \mathrm{~mol}^{-1}$ ) was purchased from HIMEDIA and stock solutions $\left(1000 \mathrm{mg} \mathrm{L}^{-1}\right)$ were prepared in deionized water. The prepared dye solution was filtrated and rested for 1-2 days before using in experiments.

\section{Sorption Experiments}

3 separate tests groups were composed in order to determine and compare MG removal, from aqueous medium, alginate microspheres (A), L.minor (L) and encapsulated L.minor (caps A+L):

group 1: contains only L.minor

group 2: contains only alginate microsphere

group 3: contains encapsulated L.minor

$20 \mathrm{mg}$ dried L.minor and microsphere was weighed and added to $50 \mathrm{~mL}$ test solution. In preliminary studies, it was decided to use 7 different concentration $(0.5,1.0,2.5,5.0,10.0,20.0$ and 50 $\mathrm{mg} \mathrm{L}^{-1}$ ) in experiments. Each test was carried out with three repetitions. The solution mixture was equilibrated by using an automatic shaker for $24 \mathrm{~h}$ at $30 \pm 2^{\circ} \mathrm{C}$ and then filtered with a $0.45 \mu \mathrm{m}$ filter. The initial and residual concentration of $\mathrm{MG}$ dye in the solution was determined by using UV-vis Spectrophotometer at $621 \mathrm{~nm}$ (Soni et al., 2014). The removal percentage (E\%) and adsorption capacity (qe) were determined as follows: (Zhou et al., 2015).

$$
\begin{aligned}
& \mathrm{E} \%=\frac{C 0-C 1}{C 0} \times 100 \\
& \mathrm{qe}=\frac{C 0-C 1}{m} \times V
\end{aligned}
$$

where $\mathrm{C} 0$ and $\mathrm{C} 1$ are initial and equilibrium concentrations of adsorbent in solution, respectively $\left(\mathrm{mg} \mathrm{L}^{-1}\right)$; qe is the adsorption capacity of the adsorbent $\left(\mathrm{mg} \mathrm{g}^{-1}\right)$; $\mathrm{m}$ is the weight of adsorbent $(\mathrm{g})$ and $\mathrm{V}$ denotes the volume of solution $(\mathrm{L})$.

\section{Statistical Analysis}

Regression analysis was a statistical process for estimating the relationships (correlation) among variables. Estimation models of removed MG amount, depending on concentration increment, were established using regression analysis. For each of the groups (L), (A) and (caps A+L), both linear and cubic models were established separately. The calculated $\mathrm{R}^{2}$ values were very large and are between 0.961-0.996 for linear models and 0.988-1.0 for cubic ones. Concentration-dependent removal efficiencies and adsorption capacities were statistically compared by non-parametric Mann-Whitney U test and statistically significant differences were interpreted. Mann- Whitney U test was preferred for the reason that the number of data was not high enough. All statistical analyzes and included graphs were obtained by using IBM SPSS 21.0 software. 


\section{RESULTS AND DISCUSSION}

\section{Assessment of Removal and Adsorption Capacity}

This study evaluates the dye removal efficiencies of the aquatic macrophyte L.minor, synthesized alginate microspheres and encapsulated L.minor. In order to determine the removal efficiency percentages and adsorption capacities of tested sorbents, particular calculations were done and removal models were established.

When the removal (\%) graph was examined; no removal was observed in (L) and (caps $\mathrm{A}+\mathrm{L}$ ) groups at $0.5 \mathrm{mg} \mathrm{L}^{-1}$ concentration, where $20 \% \mathrm{MG}$ removal was seen in (A) groups (Fig 1).
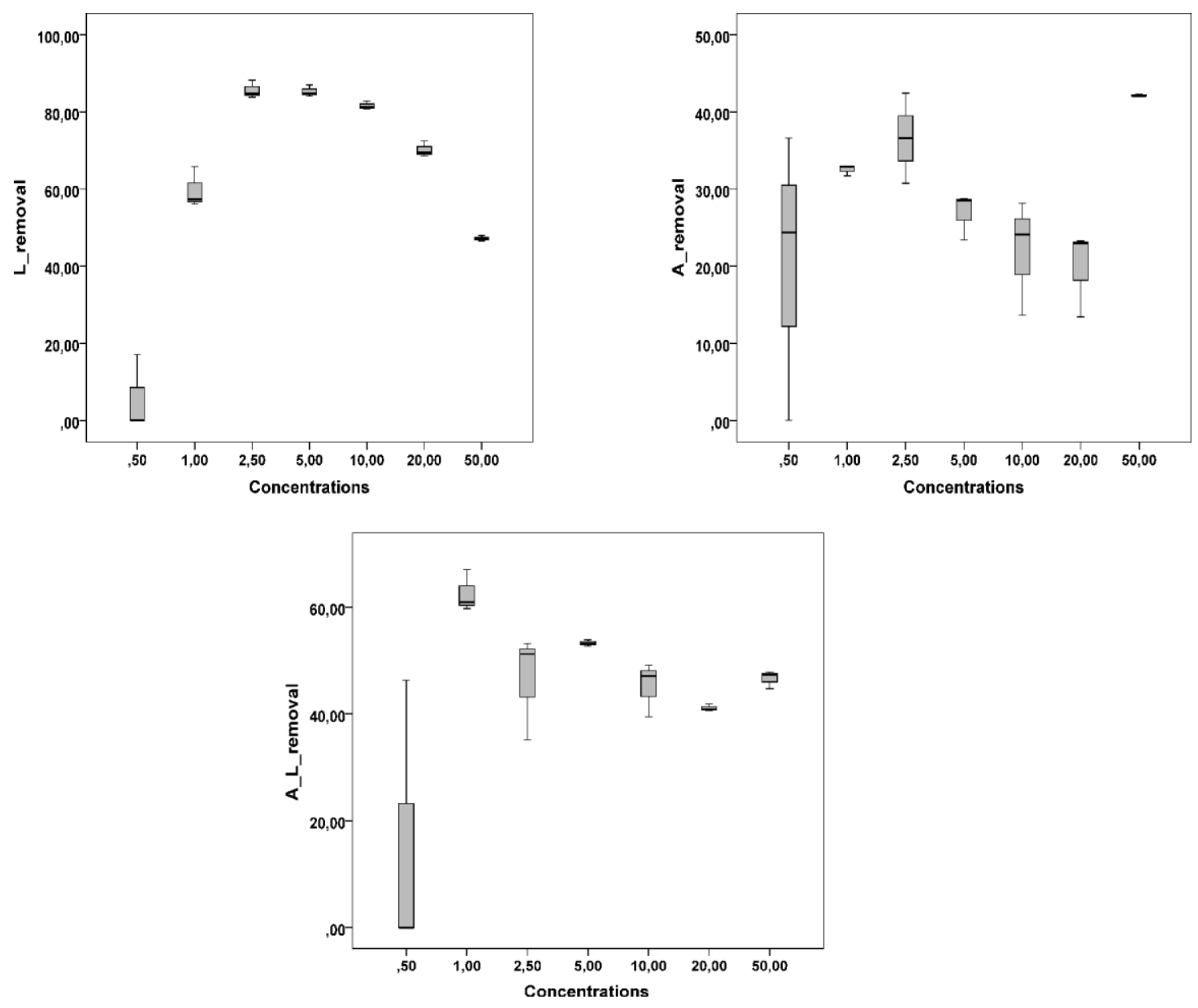

Figure 1. Concentration-dependent removal efficiencies of MG for L, A and A+L.

At all concentrations, except with the low concentrations $\left(0.5\right.$ and $\left.1.0 \mathrm{mg} \mathrm{L}^{-1}\right)$, removal efficiencies and adsorption capacities of groups were found as $\mathrm{L}>\mathrm{A}+\mathrm{L}>\mathrm{A}$ (Fig 2).

This result implies that alginate microsphere (A), alone only, is less successful in MG removal compared to other groups $(\mathrm{L}, \mathrm{A}+\mathrm{L})$ at applied concentrations. On the other hand, impressive increase in removal efficiency of microspheres at the highest concentration (almost 2 times of the efficiency at lowest concentration) is important and give rise to thought that microspheres are more efficient in contaminant removal at high concentrations. It is known that microspheres are very successful in adsorption of some metals such as strontium (Sr II) (Hong et al. 2016), $\mathrm{Cd}^{2+}, \mathrm{Hg}^{2+}, \mathrm{Pb}^{2+}$ (Ding et al., 2015) , Cr(VI) (Li et al., 2012), Ni (Yang et al., 2011) and Cu (II) (Zeng et al., 2015). They are also efficient in adsorption of dye (Ramalingam et al., 2015) like 2,5-dihydroxybenzoic acid (2,5-DHBA) 
(Tang et al., 2015). Interaction of surface functional groups, carboxyl and hydroxyl groups on alginate beads, with target metals allows the adsorption of metal ions (Vu et al., 2017; Zheng et al., 2016). The efficiency of microspheres in adsorption depends on some factors such as amount of adsorbent (Asthana et al., 2016; Ngah and Fatinathan, 2010), amount of used alginate (Kwiatkowska-Marks and Wójcik, 2014), concentration of contaminant in medium (Zhu et al., 2014), surface of the microsphere (Wang et al., 2016), time (Idris et al., 2012) and pH (Asthana et al., 2016; Ociński et al., 2016). It is stated that increase in alginate amount in beads reduces $\mathrm{Cd}$ adsorption by reducing usability of active sites that are needed for adsorption of metal ions (Kwiatkowska-Marks and Wójcik, 2014). Also it is assumed that, increase in amount of adsorbent reduces removal efficiency due to decrement of interaction potentiality between heavy metals and adsorbents (Zeng et al., 2015), but there are studies in literature against this finding (Asthana et al., 2016; Ngah and Fatinathan, 2010).

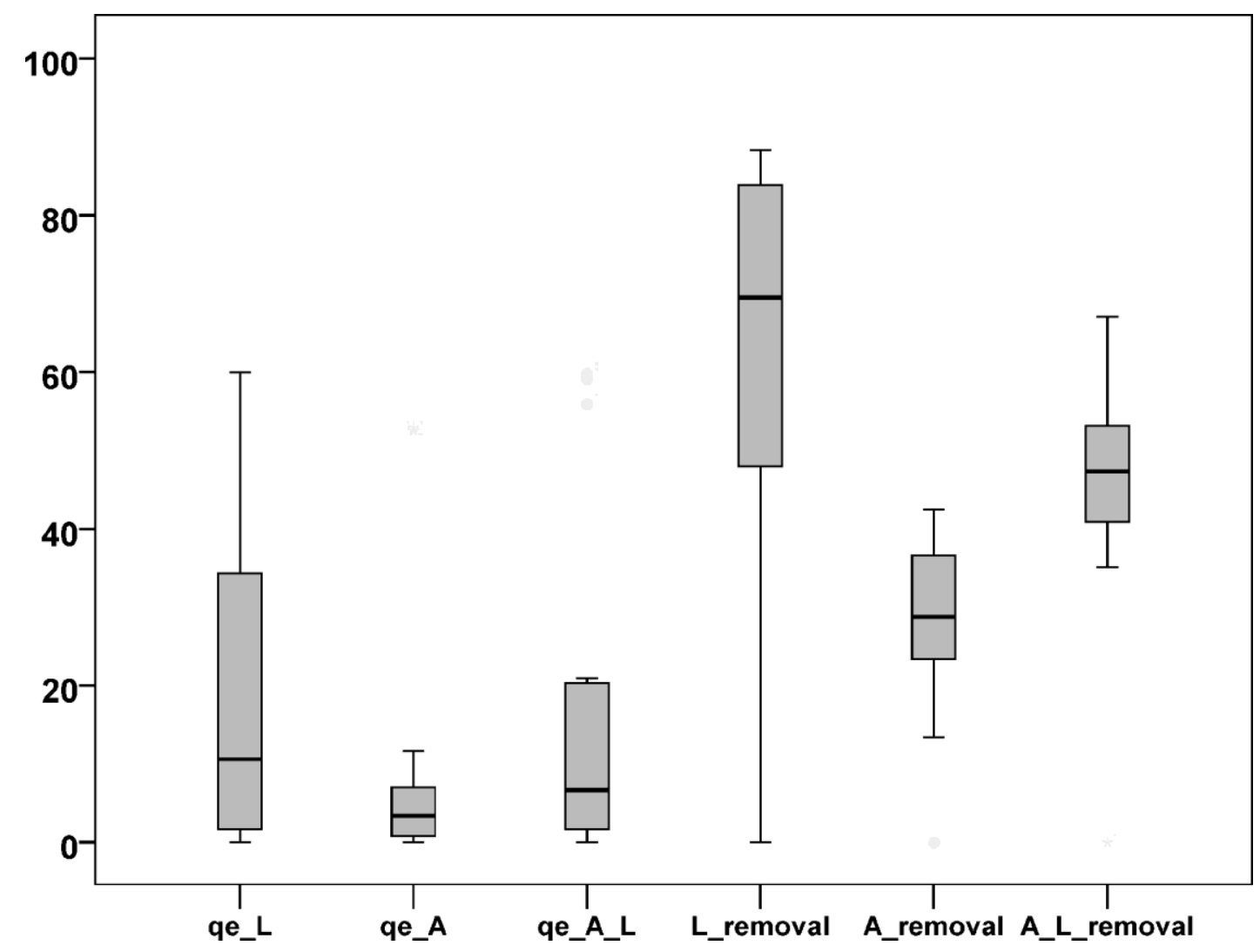

Figure 2. Comparisons of removal efficiencies and adsorption capacities (qe) for all test groups.

In this study the amount of adsorbent is fixed $(0.02 \mathrm{~g})$ and dye removal efficiency is evaluated depending on increasing contaminant concentration and different adsorbents. While removal ratios of microspheres are in increase/decrease trend depending on concentration increase, an impressive increase is observed at highest concentration $\left(50 \mathrm{mg} \mathrm{L}^{-1}\right)$ and the adsorption capacity of microspheres regularly increased as the concentration level approached $50 \mathrm{mg} \mathrm{L}^{-1}$. Both removal efficiency and adsorption capacities of the microspheres reached maximum at the applied highest concentration level. On the other hand, in contrast to this study, it is considered that increases in concentration level reduce the amount of absorbed contaminant due to saturation of binding sites (Soni et al., 2014).

Another adsorbent used in the study was the macrophyte L.minor, which is commonly preferred in removal of various contaminants from medium due to its high removal capacity (Bokhari et al., 2016; Török et al., 2015; Üçüncü et al., 2014; Üçüncü et al., 2013). L.minor also performed a high MG removal 
efficiency, at applied concentration levels, in this study. The highest removal percentages, $(70,22-85,69$ $\%)$ at 2.5, 5.0, 10.0 and $20.0 \mathrm{mg} \mathrm{L}^{-1}$ concentrations, were observed in groups containing Lemna (L). At highest concentration $50.0 \mathrm{mg} \mathrm{L}^{-1}$; while high removal percentages of (L) groups tend to decrease, removal percentages of (A) groups approached with an impressive increase to ones of groups $(\mathrm{A}+\mathrm{L})$ and (L). In other words, the concentration level at which the removal percentages of the groups are close, and that is $50.0 \mathrm{mg} \mathrm{L}^{-1}$. It is considered that; the increments observed in removal percentage of (L) at highest concentration are due to saturation of Lemna at increasing concentration levels. In a conducted study concerning malachite removal, at the applied lowest concentration (40 $\left.\mathrm{mg} \mathrm{L}^{-1}\right)$ Lemna performed the best removal efficiency with a percentage of $98 \%$ but the increases in concentration $\left(190,300 \mathrm{mg} \mathrm{L}^{-}\right.$ ${ }^{1}$ ) reduced removal efficiency (Török et al., 2015).

It can be stated that (L) groups are more successful in MG removal compared to (A) groups. However; after a certain concentration level (over $5.0 \mathrm{mg} \mathrm{L}^{-1}$ ) decreases in removal efficiency of (L) groups and impressive increases in removal percentages and adsorption capacities of (A) groups state that microspheres are more successful than Lemna at high concentrations. One other important finding is that the encapsulation of Lemna by alginate microspheres has increased adsorption capacity and removal efficiency of microspheres. Even the removal efficiency of microspheres, in which Lemna encapsulated, are almost 2 times increased compared to (A) groups, still not reached to ones containing only Lemna (L). This finding can be interpreted as follows; encapsulation of Lemna has relatively reduced interaction of Lemna with dye in medium, where actually removal efficiency of Lemna is better than microsphere due to conditions of the conducted study.

When adsorption capacities were examined it was seen that adsorption capacities were increased as the initial concentration level increases $(\mathrm{p}<0.0 .5)$ (Fig 3).

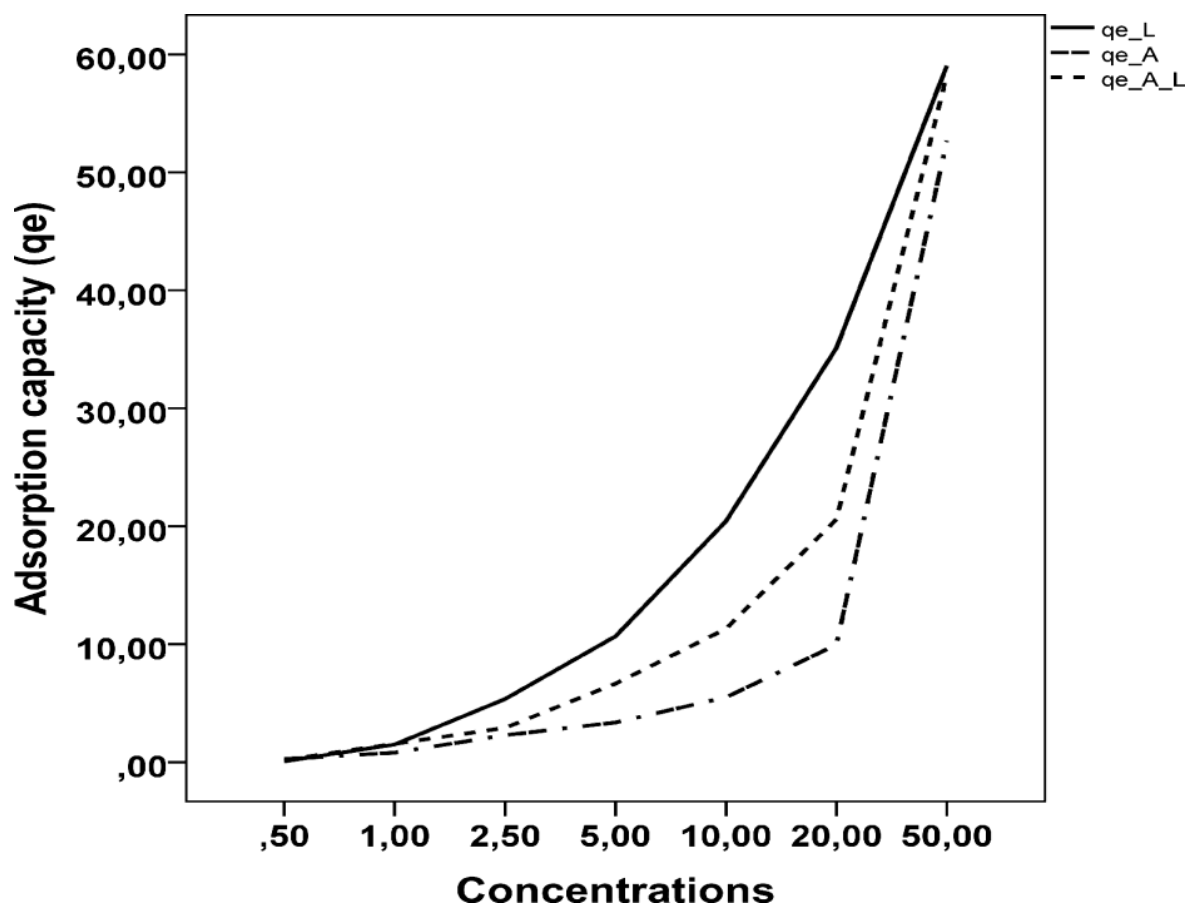

Figure 3. Concentration-dependent adsorption capacities of L, A and A+L.

This finding was supported by studies, in which $\mathrm{Cu}^{2+}$ adsorption by microspheres (Zheng et al., 2016) and removal of fluoride and uranium using microspheres, (Wu et al., 2016) were investigated. On the other hand, other studies (Dubey et al., 2016) indicate that increase in initial concentration decreases 
adsorption capacity. In a study it was also reported that increases in initial concentration rapidly increased adsorption capacity and then reached steady-state (Wu et al., 2016). Interpreted this result as, that the increase in initial concentration has composed an impulse in mass transfer resistance among solid and liquid phases and then adsorption capacity has saturation trend (Wu et al., 2016).

In this present study it was observed that the adsorption capacities were parallel to the removal efficiencies and the smallest qe (adsorption capacity) value was found in microspheres. In removal results, an impressive increase observed in adsorption capacities of (A) groups at the highest concentration. We believe that it was due to high contact potentiality of microsphere surfaces with increasing contaminant concentration.

While a significant difference was found in all comparisons of $0.5 \mathrm{mg} \mathrm{L}^{-1}$ and $1.0 \mathrm{mg} \mathrm{L}^{-1}$, no statistically significant difference was found the other concentrations $\left(2.5,5.0,10.0,20.0\right.$ and $50 \mathrm{mg} \mathrm{L}^{-}$ ${ }^{1}$ ) for qe according to MWU $(\mathrm{p}<0.05)$. It was determined that the significant difference was found to be higher in favor of high concentrations for qe. Removal efficiencies were similar to qe comparisons for $0.5 \mathrm{mg} \mathrm{L}^{-1}$. However, it was detected removal values at low concentrations were more statistically higher than the higher concentrations at $1.0 \mathrm{mg} \mathrm{L}^{-1}$. Additionally, no difference was observed between 1.0-2.5 $\mathrm{mg} \mathrm{L}^{-1}$ (as an exception). There was no statistically significant difference was observed in the other concentrations $\left(2.5,5.0,10.0,20.0\right.$ and $\left.50 \mathrm{mg} \mathrm{L}^{-1}\right)$ as in qe.

\section{Regression Models of Removal Efficiencies}

Concentration-dependent estimation models of all groups, which were exposed to 7 different concentration of MG, were established and these models were analyzed. Estimation models were in linear and cubic forms (Fig 4-5).

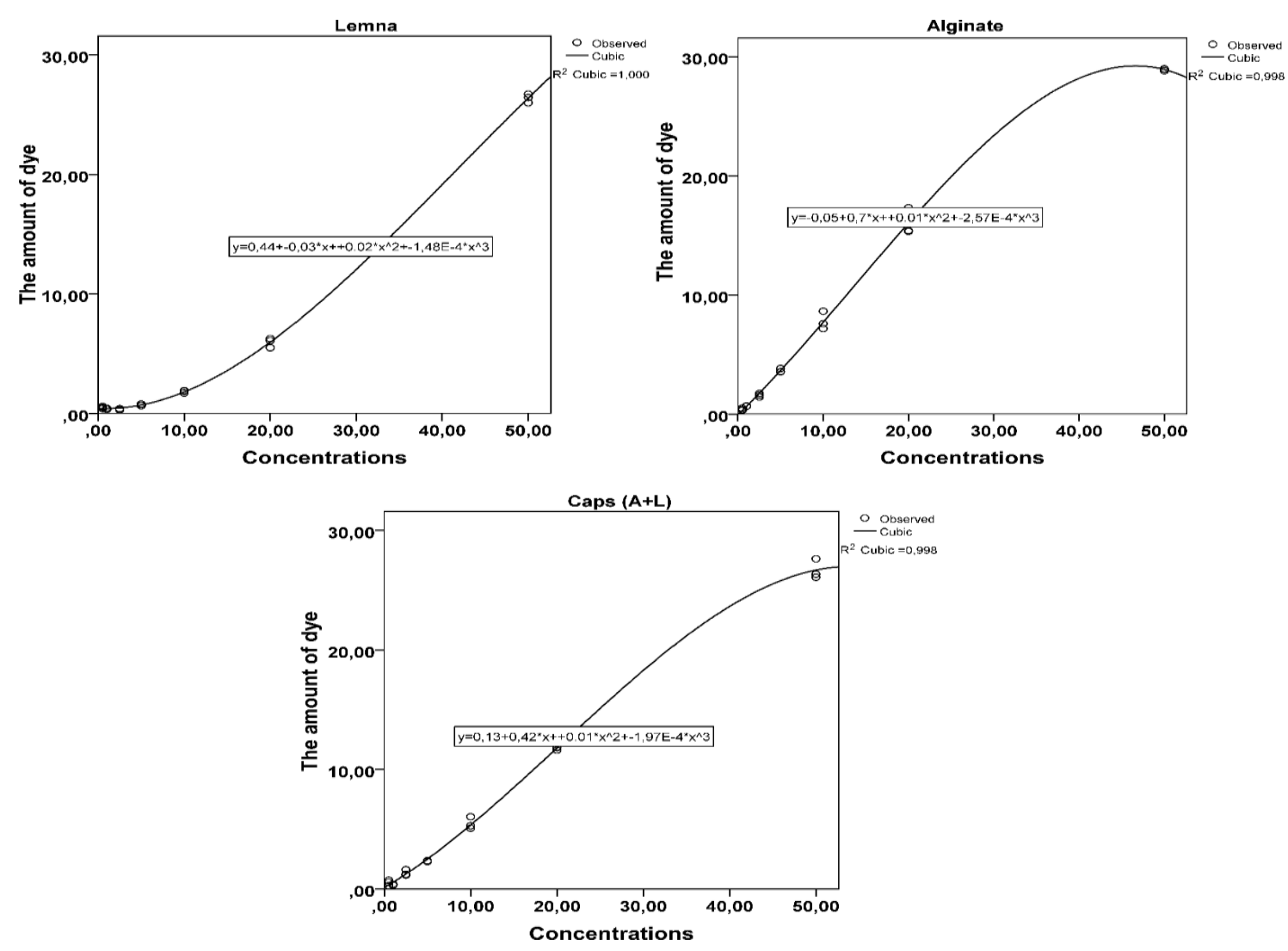

Figure 4. Cubic estimation models of concentration-dependent removal efficiencies of MG for all test groups. 

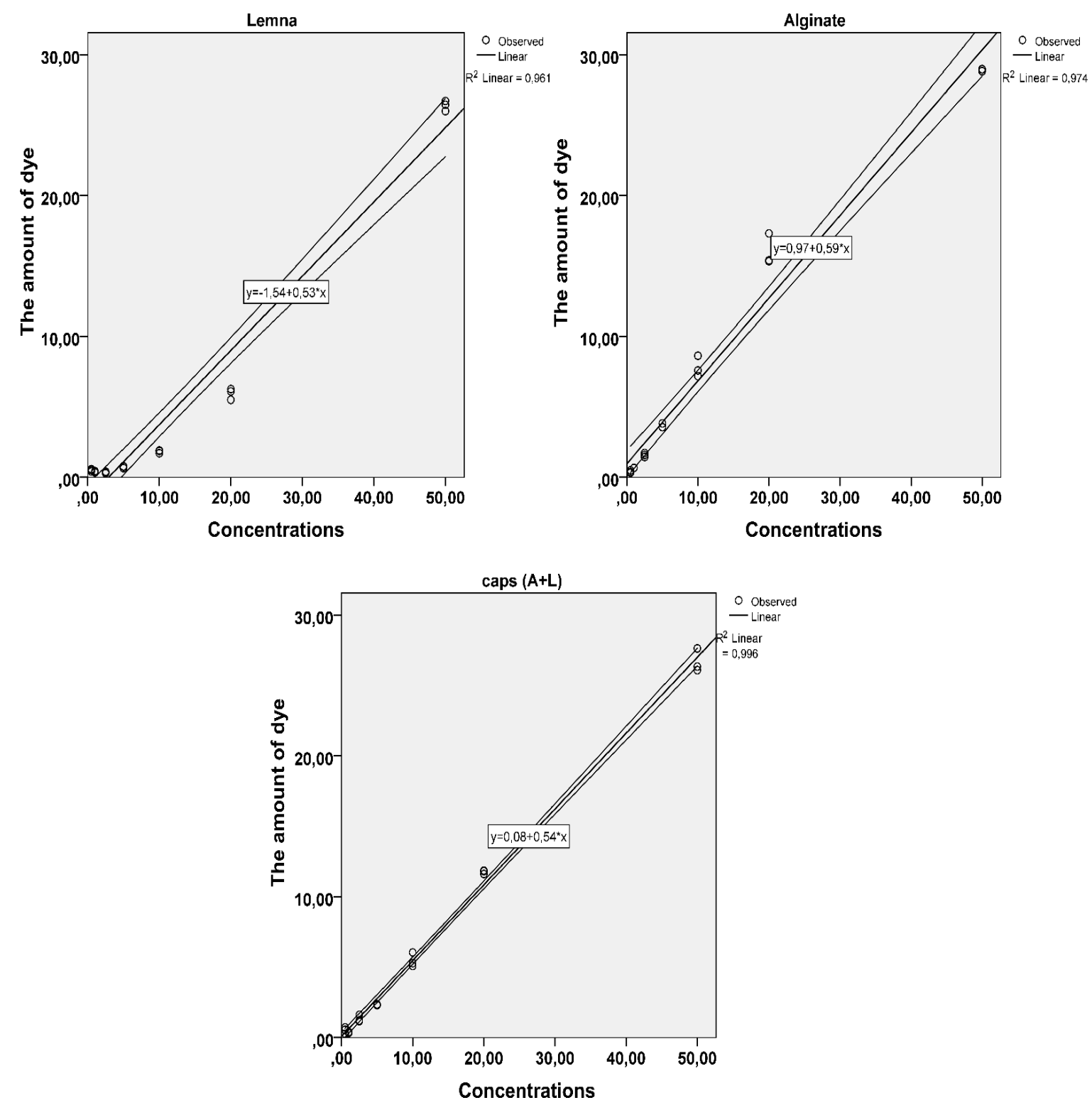

Figure 5. Lineer estimation models of concentration-dependent removal efficiencies of MG for all test groups.

When regression analysis results examined it was seen that $\mathrm{R}^{2}$ values of cubic models were higher (0.988-1.0), hence it was more appropriate for the data of this study. When regression figures were examined it was clearly seen that, the removal efficiency (\%) and adsorption capacity (qe) results of the study support regression models. In removal of $\mathrm{MG}$, it can be stated that at all concentrations except with lowest and highest concentrations, (L) groups were more successful than $(A)$ and $(A+L)$ groups.

Furthermore regression estimation models show that in removal of MG from medium, (A) and $(A+L)$ test groups have similar trends. No regular increases or decreases were observed in concentration dependent removal efficiency, where $(A)$ and $(A+L)$ groups have fluctuating trend.

\section{CONCLUSION}

In this study L.minor, alginate microspheres and alginate microsphere encapsulated L.minor were used as adsorbents in the removal process of toxic malachite green contaminant from medium. Removal efficiency models were established with regression analysis.

At all concentrations except with lowest concentrations, removal efficiency and adsorption capacities of the tested groups were ordered as $\mathrm{L}>\mathrm{A}+\mathrm{L}>\mathrm{A}$. According to this result; alginate 
microsphere (A) alone only was less successful in malachite green removal compared to other groups $(\mathrm{L}, \mathrm{A}+\mathrm{L})$ at all applied concentrations. However, serious increase in removal efficiency of microspheres at highest concentration indicated that microspheres can be more successful in contaminant removal at high concentrations. The highest removal percentages (70,22-85,69\%) were observed in (L) groups. Encapsulation of Lemna with alginate microspheres has increased the removal efficiency of microspheres but still not reached the removal efficiency values of (L) groups. According to the regression modeling results; the $\mathrm{R}^{2}$ values of cubic models were higher and removal efficiency (\%), adsorption capacity (qe) results support the results of regression models. In removal process of MG from medium, it was observed that $(\mathrm{A})$ and $(\mathrm{A}+\mathrm{L})$ test groups have similar trends.

It was very important to develop the remediation studies, which was an effective method in removal of contaminants, with new studies and methods. This present study states that using effective (good) sorbents in encapsulation process, can give successful results in removal of contaminants such as MG.

\section{REFERENCES}

Asthana A, Verma R, Singh AK, Susan MABH, Adhikari R, 2016. Silver Nanoparticle Entrapped Calcium-Alginate Beads for Fe(II) Removal via Adsorption. Macromolecular Symposia, 366(1):42-51.

Biradar SP, Rane NR, Patil TS, Khandare RV, Govindwar SP, Pawar PK, 2016. Herbal augmentation enhances malachite green biodegradation efficacy of Saccharomyces cerevisiae. Biologia, 71(5):475-483.

Bokhari SH, Ahmad I, Mahmood-Ul-Hassan M, Mohammad A, 2016. Phytoremediation potential of Lemna minor L. for heavy metals. Int. J. Phyto, 18(1):25-32.

Clar JG, Li X, Impellitteri CA, Bennett-Stamper C, Luxton TP, 2016. Copper nanoparticle induced cytotoxicity to nitrifying bacteria in wastewater treatment: A mechanistic copper speciation study by X-ray absorption spectroscopy. Environmental Science and Technology, 50(17):9105-9113.

Ding Y, Zhu W, Xu Y, Qian X, 2015. A small molecular fluorescent sensor functionalized silica microsphere for detection and removal of mercury, cadmium, and lead ions in aqueous solutions. Sensors and Actuators, B: Chemical, 220:762-771.

Dubey R, Bajpai J, Bajpai AK, 2016. Chitosan-alginate nanoparticles (CANPs) as potential nanosorbent for removal of $\mathrm{Hg}$ (II) ions. Environ. Nanotechnol. Monit. Manag, 6:32-44.

Hong HJ, Ryu J, Park IS, Ryu, Chung KS, Kim BG, 2016.Investigation of the strontium ( $\operatorname{Sr}(\mathrm{II})$ ) adsorption of an alginate microsphere as a low-cost adsorbent for removal and recovery from seawater. J Environ Manage, 165:263-270.

Idris A, Ismail NSM, Hassan N, Misran E, Ngomsik A-F, 2012. Synthesis of magnetic alginate beads based on maghemite nanoparticles for $\mathrm{Pb}$ (II) removal in aqueous solution. Journal of Industrial and Engineering Chemistry, 18(5):1582-1589.

Issa AA, Al-Degs YS, Al-Ghouti MA, Olimat AAM, 2014. Studying competitive sorption behavior of methylene blue and malachite green using multivariate calibration. Chemical Engineering Journal, 240:554-564.

Jerold M, Sivasubramanian V, 2016. Biosorption of malachite green from aqueous solution using brown marine macro algae Sargassum swartzii. Desalin. Water Treat, 1-13.

Khan TA, Rahman R, Ali I, Khan EA, Mukhlif AA, 2014. Removal of malachite green from aqueous solution using waste pea shells as low-cost adsorbent - adsorption isotherms and dynamics. Toxicological and Environmental Chemistry, 96(4):569-578. 
Kwiatkowska-Marks S, Wójcik M, 2014. Removal of Cadmium(II) from Aqueous Solutions by Calcium Alginate Beads. Separation Science and Technology, 49(14):2204-2211.

Li C, Zhang Y, Peng J, Wu H, Li J, Zhai M, 2012. Adsorption of Cr(VI) using cellulose microspherebased adsorbent prepared by radiation-induced grafting. Radiation Physics and Chemistry, 81(8):967-970.

Li X, Li Y, Ye Z, 2011. Preparation of macroporous bead adsorbents based on poly(vinyl alcohol)/chitosan and their adsorption properties for heavy metals from aqueous solution. Chemical Engineering Journal, 178:60-68.

Liang Z, Zhaob Z, Sun T, Shi W, Cui F, 2016. Adsorption of quinolone antibiotics in spherical mesoporous silica: Effects of the retained template and its alkyl chain length. J. Hazard. Mater, 305:8-14.

Naushad M, Ali Khan M, Abdullah Alothman Z, Rizwan Khan M, Kumar M, 2015. Adsorption of methylene blue on chemically modified pine nut shells in single and binary systems: isotherms, kinetics, and thermodynamic studies. Desalin. Water Treat, 57(34): 15848-15861.

Ngah WS, Fatinathan S, 2010. Adsorption characterization of $\mathrm{Pb}$ (II) and $\mathrm{Cu}$ (II) ions onto chitosantripolyphosphate beads: Kinetic, equilibrium and thermodynamic studies. J Environ Manage, 91(4):958-69.

Ociński D, Jacukowicz-Sobala I, Kociołek-Balawejder E, 2016. Alginate beads containing water treatment residuals for arsenic removal from water-formation and adsorption studies. Environ. Sci. Pollut. Res, 1-13.

Pandey A, Bera D, Shukla A, Ray L, 2015. Studies on Cr(VI), Pb(II) and Cu(II) adsorption-desorption using calcium alginate as biopolymer. Chemical Speciation \& Bioavailability, 19(1):17-24.

Ramalingam B, Khan MMR, Mondal B, Mandal AB, Das SK, 2015. Facile Synthesis of Silver Nanoparticles Decorated Magnetic-Chitosan Microsphere for Efficient Removal of Dyes and Microbial Contaminants. ACS Sustainable Chemistry and Engineering, 3(9):2291-2302.

Soni A, Tiwari A, Bajpai AK, 2014. Removal of Malachite green from aqueous solution using nanoiron oxide-loaded alginate microspheres: Batch and column studies. Research on Chemical Intermediates, 40(3):913-930.

Tang S, Chia GH, Lee HK, 2015. Magnetic core-shell iron(II,III) oxide@layered double oxide microspheres for removal of 2,5-dihydroxybenzoic acid from aqueous solutions. J. Colloid Interface Sci, 437:316-323.

Török A, Buta E, Indolean C, Tonk S, Silaghi-Dumitrescu L, Majdik C, 2015. Biological removal of triphenylmethane dyes from aqueous solution by Lemna minor. Acta Chimica Slovenica, 62(2):452-461.

Üçüncü E, Özkan AD, Kurşungöz C, Ülger ZE, Ölmez TT, Tekinay T, Ortaç B, Tunca E, 2014. Effects of laser ablated silver nanoparticles on Lemna minor. Chemosphere, 108:251-257.

Üçüncü E, Tunca E, Fikirdeşici S, Özkan AD, Altindağ A, 2013. Phytoremediation of $\mathrm{Cu}, \mathrm{Cr}$ and $\mathrm{Pb}$ mixtures by lemna minor. Bull Environ Contam Toxicol, 91(5):600-604.

Vu HC, Dwivedi AD, Le TT, Seo SH, Kim EJ, Chang YS, 2017. Magnetite graphene oxide encapsulated in alginate beads for enhanced adsorption of $\mathrm{Cr}(\mathrm{VI})$ and $\mathrm{As}(\mathrm{V})$ from aqueous solutions: Role of crosslinking metal cations in pH control. Chemical Engineering Journal, 307:220-229.

Wang F, Lu X, Li XY, 2016. Selective removals of heavy metals ( $\mathrm{Pb} 2+, \mathrm{Cu} 2+$, and $\mathrm{Cd} 2+$ ) from wastewater by gelation with alginate for effective metal recovery. J. Hazard. Mater, 308:75-83. 
Wu L, Lin X, Zhou X, Luo X, 2016. Removal of uranium and fluorine from wastewater by doublefunctional microsphere adsorbent of SA/CMC loaded with calcium and aluminum. Applied Surface Science, 384:466-479.

Yang F, Liu H, Qu J, Paul Chen J, 2011.Preparation and characterization of chitosan encapsulated Sargassum sp. biosorbent for nickel ions sorption. Bioresour Technol, 102(3):2821-2828.

Zeng L, Chen Y, Zhang Q, Guo X, Peng Y, Xiao H, Chen X, Luo J, 2015. Adsorption of Cd(II), Cu(II) and $\mathrm{Ni}(\mathrm{II})$ ions by cross-linking chitosan/rectorite nano-hybrid composite microspheres. Carbohydrate polymers, 130:333-343.

Zheng E, Dang Q, Liu C, Fan B, Yan J, Yu Z, Zhang H, 2016. Preparation and evaluation of adipic acid dihydrazide cross-linked carboxymethyl chitosan microspheres for copper ion adsorption. Colloids Surf. A Physicochem. Eng. Asp, 502:34-43.

Zhou L, Wang Y, Liu Z, Huang Q, 2009. Characteristics of equilibrium, kinetics studies for adsorption of $\mathrm{Hg}(\mathrm{II}), \mathrm{Cu}(\mathrm{II})$, and $\mathrm{Ni}(\mathrm{II})$ ions by thiourea-modified magnetic chitosan microspheres. J Hazard Mater, 161(2-3):995-1002.

Zhou Y, Min Y, Qiao H, Huang Q, Wang E, Ma T, 2015. Improved removal of malachite green from aqueous solution using chemically modified cellulose by anhydride. Int J Biol Macromol, 74:271277.

Zhu H, Fu Y, Jiang R, Yao J, Xiao L, Zeng G, 2014. Optimization of Copper(II) Adsorption onto Novel Magnetic Calcium Alginate/Maghemite Hydrogel Beads Using Response Surface Methodology. Industrial \& Engineering Chemistry Research, 53(10):4059-4066. 